\title{
Performance Comparison of Four Kinds of Straw/PLA/PBAT Wood Plastic Composites
}

\begin{abstract}
Jianan Feng, Weixing Zhang, Lei Wang, and Chunxia He *
Utilizing four kinds of straw fibers (sorghum, rice, corn, and soybean) as filling fibers, polylactic acid (PLA) and poly (adipic acid)/polybutylene terephthalate (PBAT) in a mixture (7:3) were used as matrix to prepare composite materials by a hot pressing molding process. The mechanical properties, and thermal stability of the four fiber-filled composites were evaluated. The composites had high interfacial quality and no obvious voids. The soybean straw/PLA/PBAT composite had the best interfacial quality. PLA/PBAT-based composite materials were examined. The experimental results show that the soybean straw/PLA/PBAT composite had the best tensile strength, bending strength, and impact strength (14.3 MPa, 19.5 MPa and $3.23 \mathrm{KJ} \cdot \mathrm{m}^{-2}$, respectively), which was $25.3 \%, 14.6 \%$, and $27.8 \%$ higher than that of the corn straw/PLA/PBAT composite. The thermal stability of the corn straw/PLA/PBAT composite was the best, with an initial decomposition temperature of $286^{\circ} \mathrm{C}$, and the residual amount was $7.3 \%$.
\end{abstract}

Keywords: Crop straw; PLA; Microstructure; FTIR; Thermal stability

Contact information: College of Engineering, Nanjing Agricultural University, Nanjing, P. R. China; *Corresponding author: chunxiahe@tom.com

\section{INTRODUCTION}

With the gradual shortage of petroleum energy and the environmental crisis in recent years, there is much research on biomass fully degradable composites. Polylactic acid (PLA) is currently the most promising biomass polymer material. Its main raw material is lactic acid, which can be formed by fermentation of corn starch, rice, etc. (Lee et al. 2016; Murariu and Dubois 2016). It can also be extracted from the cellulose of agricultural wastes. Polylactic acid (PLA) can be $100 \%$ degraded. The main products of combustion are $\mathrm{CO}_{2}$ and $\mathrm{H}_{2} \mathrm{O}$ (Dharmalingam et al. 2015). It is environmentally friendly, non-toxic, and harmless to humans. Polylactic acid has good thermoplasticity and is suitable for processing. However, the impact strength and heat resistance of PLA are poor. At present, researches have mostly mixed poly $\backslash$ (adipic acid)/butyl terephthalate (PBAT) with PLA, and modified PLA with PBAT's high toughness and good heat resistance to improve the application range of PLA composites (Cardoso et al. 2017). Crop straw is agricultural waste that is available in large quantities, low in price, and renewable. Research on straw fiber composite materials is of great significance for the reuse of agricultural waste.

In recent years, the main research directions of polylactic acid (PLA) biomass composites are FDM molding and impact modification of polylactic acid. Torres et al. (2015) studied the influence of changing FDM's three technological parameters on the torsional properties of PLA materials, demonstrating the ability to produce parts with mechanical properties at or near those of bulk PLA. Wach et al. (2018) investigated the 
possibility of enhancing mechanical properties of PLA samples processed by a rapid manufacturing (RM) technique by increasing PLA crystallinity degree via thermal annealing, finding that polymer processed at $215^{\circ} \mathrm{C}$ increases the degree of crystallinity to the maximum attainable level. Rasselet et al. (2019) studied the properties of the PLA/PA11 blends compatibilized with Joncryl. The results showed that samples only show strong rigidity, whereas their reinforcement and elongation at break are poor. In the research of plant fiber reinforced PLA composites, hemp fibers are mostly used. Xu et al. (2019) used a new composite lamination process to improve the mechanical properties of hemp fiber reinforced polylactic acid composites, and the results showed that the adhesion between fiber and matrix is enhanced and the mechanical properties are obviously improved by this composite process. Zhu et al. (2018) studied the effects of cellulose, hemicellulose, and lignin contents on the tensile strength of sisal fiber and the interfacial strength between SFS and polylactic acid (PLA) matrix. The appropriate cellulose, hemicellulose, and lignin contents had good effects on the tensile strength of SFS and the interfacial quality between SFS and PLA matrix.

In the related research, the PLA composites filler mainly uses hemp fibers or PLA is used as matrix of composites alone. In this paper, a PLA/PBAT blend is used as matrix, and then alkali treatment, silane and PLA-gMAH interface modification are carried out in parallel. Four common crop straws are used as filling materials. Various properties of different filled straw fiber composite are compared. The purpose of this study was to lay a foundation for further research.

\section{EXPERIMENTAL}

\section{Materials}

Straw powder from four crops (rice, corn, sorghum, and soybean), size 100 mesh, were procured from Lianyungang, Jiangsu Province, China. Polylactic acid (PLA, 4032D), size 100 mesh, was procured from Zhonglian Plastic Raw Materials, Dongguan, Guangdong Province, China; poly(adipic acid)/butyl terephthalate (PBAT), size 100 mesh, was procured from prudential plastic additives, Dongguan, Guangdong Province, China. Anhydrous ethanol (95\%, liquid) was procured from Wuxi Yatai United Chemical Co., Ltd., Wuxi, Jiangsu Province, China; silane coupling agent (KH-590, liquid) was procured from Huai'an Heyuan Chemical Co., Ltd, Huaian, Jiangsu Province, China. PLAgMAH(5568-K), size 100 mesh, Shenzhen ShengBang Plastic Raw Material, Shenzhen, Guangdong Province, China.

\section{Preparation of straw fiber/PLA/PBAT composites}

The straw powder was sieved through a 100 -mesh size and placed into a $10 \mathrm{wt} \%$ $\mathrm{NaOH}$ aqueous solution for $12 \mathrm{~h}$. After filtering the straw powder and washing it to neutrality, it was oven-dried at $80{ }^{\circ} \mathrm{C}$ for $12 \mathrm{~h}$. Straw powder was modified with $5 \mathrm{wt} \%$ silane ethanol solution and dried in an oven at $80{ }^{\circ} \mathrm{C}$. Matrix ratio: PLA(size 100 mesh) and PBAT(size 100 mesh) were mixed in a ratio of 7:3. The ratio of the composite to the plant fiber to the matrix was $7: 3$. The specific composition percentage by dry mass of the composite is shown in Table 1 . Then these materials were put into a mixer to be evenly mixed for $10 \mathrm{~min}$. The uniformly mixed materials were filled into a mold and hot pressed at $160{ }^{\circ} \mathrm{C}$ and $10 \mathrm{MPa}$ for $15 \mathrm{~min}$. 
Table 1. Composites Ingredients

\begin{tabular}{|c|c|c|c|c|}
\hline Fiber & PLA & PBAT & Fiber weight & PLA-gMAH \\
\hline Sorghum & 49 & 21 & 30 & 1 \\
\hline Rice & 49 & 21 & 30 & 1 \\
\hline Corn & 49 & 21 & 30 & 1 \\
\hline Soybean & 49 & 21 & 30 & 1 \\
\hline
\end{tabular}

\section{Microscopic Morphology of Tensile Section}

The surface to be measured was treated by spraying gold with an ion sputtering instrument (E-1010, Hitachi, Japan) for $1 \mathrm{~min}$, and the microscopic morphology of tensile section and wear surface of the sample was observed with a field emission scanning electron microscope (S-4800, Hitachi, Tokyo, Japan).

\section{Mechanical Properties}

Dimensions of samples prepared for the mechanical test were $100 \mathrm{~mm} * 10 \mathrm{~mm} * 7 \mathrm{~mm}$. Referring to GB/T 1040.1-2006 and GB/T9341-2008, respectively, the tensile strength and bending strength of composites were tested by a universal testing machine (CMT6104, Metz Industrial System (China) Co., Ltd., Shanghai, China). The test rate was set at 2 $\mathrm{mm} / \mathrm{min}$. According to GB/T 1043.1-2008, the impact strength of composites was tested by an impact testing machine (XJJ-5, Chengde Jinjian Testing Instrument Co., Ltd., Chengde, China). The experiment was repeated 3 times to obtain the mean value.

\section{FTIR}

The samples were oven-dried at $80{ }^{\circ} \mathrm{C}$ for $6 \mathrm{~h}$. A total of $0.002 \mathrm{~g}$ of sample powder was mixed with $0.2 \mathrm{~g}$ of potassium bromide and compacted into tablets. The samples were tested with a Fourier transform infrared spectrometer (Nicoleis10, Shanghai DM Chemical Technology Co., Ltd., Shanghai, China) over a range from 400 to $4000 \mathrm{~cm}^{-1}$, with a resolution of $4 \mathrm{~cm}^{-1}$ and 16 scans.

\section{Thermogravimetry}

The thermogravimetric curve (TG) of the composite material was determined by a chip analyzer (STA449 F3, Netzsch, Shanghai, China). The sample mass was 10 to $20 \mathrm{mg}$, and the heating rate was $20^{\circ} \mathrm{C} / \mathrm{min}$. The purge gas and protective gas rate was $20 \mathrm{~mL} / \mathrm{min}$, and the temperature range was 30 to $800^{\circ} \mathrm{C}$.

\section{RESULTS AND DISCUSSION}

\section{FTIR Analysis}

Figure 1 shows the infrared spectrum of straw fiber. The figures show that all fibers have strong absorption peaks in the range 3300 to $3000 \mathrm{~cm}^{-1}$, and the waveband corresponds to the telescopic vibration absorption peak of the hydroxyl groups (-OH). The hydroxyl groups mainly are present in cellulose, hemicellulose, and other components in straw fibers (Xu et al. 2009); The double peaks near $2900 \mathrm{~cm}^{-1}$ are absorption peaks of methyl - $\mathrm{CH} 3$ and methylene $-\mathrm{CH} 2$, which are also characteristic absorption peaks of cellulose (Wang and Liu 2015). From $1750 \mathrm{~cm}^{-1}$ to $1650 \mathrm{~cm}^{-1}$ is the stretching vibration peak of carbonyl in the fiber (Kolling 1992), which mainly comes from hemicellulose and grease on the fiber surface. 


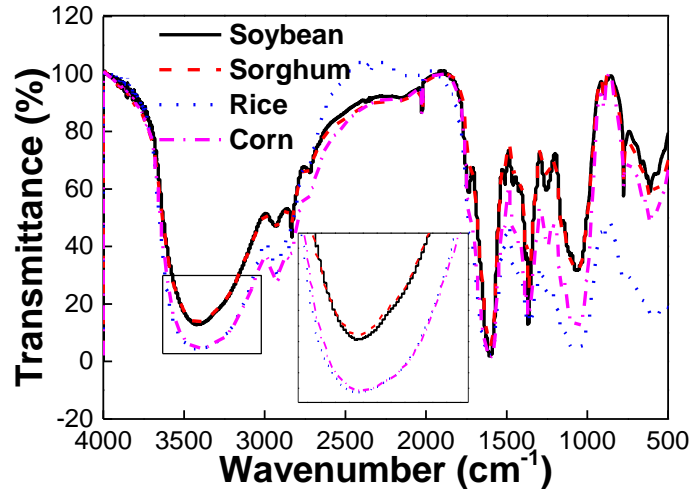

(a)

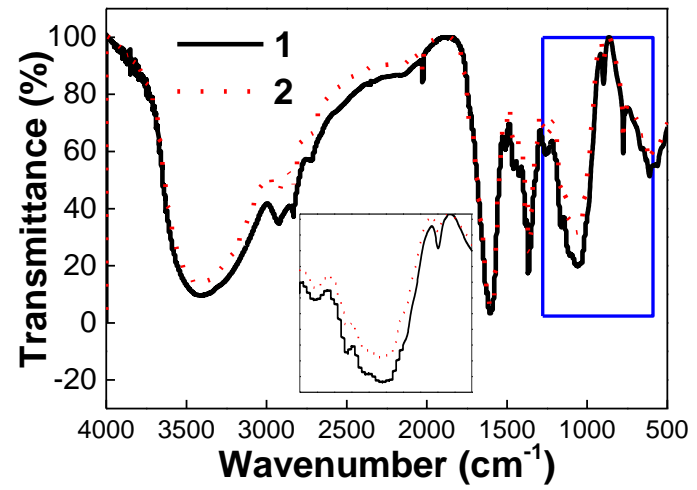

(c)

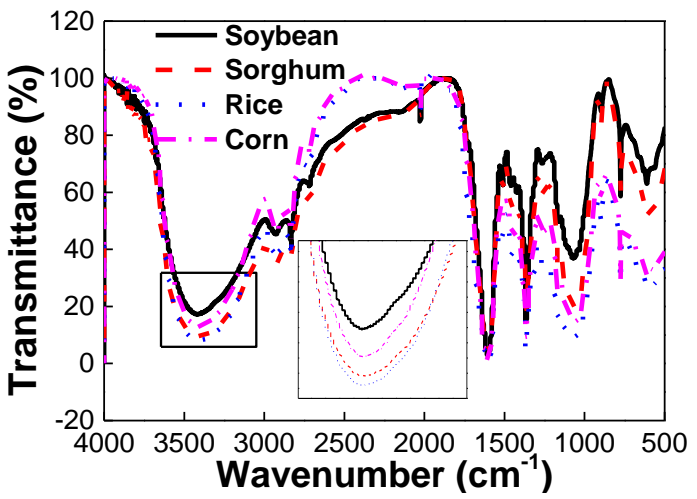

(b)

Fig. 1. FTIR spectra of the different samples. (a) untreated straw; (b) treated straw; (c) 1:treated sorghum straw, 2:untreated sorghum straw

Taking sorghum straw (Fig. 1c) as an example, the permeability of the treated fiber at 3300 to $3000 \mathrm{~cm}^{-1}$ was significantly enhanced. The reason was that alkali treatment dissolved out the cementing matter in the fiber and destroyed the hydroxyl groups in the cellulose molecules at the same time (Chen et al. 1998). The opening of some hydrogen bonds made the fiber swell. The hydrolyzed silane was easier to combine with the hydroxyl groups in the fiber to form new hydrogen bonds, thus improving fibers binding ability and hydrophobicity. There was no obvious change in the bimodal around $2900 \mathrm{~cm}^{-1}$. Except for corn straw fiber, the absorption intensity of the other three fibers in this waveband slightly increased, which shows that the cellulose content in the modified fiber increases. The absorption intensity of carbonyl group at 1750 to $1650 \mathrm{~cm}^{-1}$ was lower than that before treatment; the reason was that alkali treatment can wash away the oily layer on the fiber surface. Si-O-Si has antisymmetric and symmetrical two stretching vibration peaks in 1100 to $1000 \mathrm{~cm}^{-1}$ and 880 to $780 \mathrm{~cm}^{-1}$, and the vibration absorption peaks of Si-C at 870 to 690 $\mathrm{cm}^{-1}$ showed little change. Although KH590 adds Si-containing groups, alkali treatment also washes away Si-containing impurities such as silt on the surface of straw. The characteristic group -SH of KH590 is difficult to be observed in the spectrogram due to its weak absorbance peak.

\section{Physico-mechanical Properties}

The mechanical properties of the straw/PLA/PBAT composites are shown in Fig. 2. The tensile strength, flexural strength, and impact strength of soybean straw/PLA/PBAT 
composites were better than those of the other three composites, reaching 14.3 MPa, 19.5 $\mathrm{MPa}$, and $3.2 \mathrm{KJ} \cdot \mathrm{m}^{-2}$, respectively. With the same matrix condition, the strength of the fiber had a significant impact on the composite. The mechanical properties of straw fiber mainly depend on the contents of cellulose and lignin. Cellulose mainly improves the strength of fiber, while lignin is negatively correlated with tensile strength (Ge et al. 2016). Soybean straw fiber has the highest contents of cellulose (47.8\%) among the four straw components (Li et al. 2011; Jiang et al. 2017). The strength values of soybean straw fiber were the best, which can effectively enhance the mechanical properties of composites, as shown in Fig. 2. In addition soybean straw/PLA/PBAT composite had the best interfacial quality. The external force can be uniformly transmitted between the fiber and the matrix, while stress concentration is effectively avoided. Corn straw/PLA/PBAT composites had the worst mechanical properties because the corn straw inner core layer is soft, low in strength and loose in fiber structure. Sorghum straw/PLA/PBAT composite and rice straw /PLA/PBAT composite had little difference in mechanical properties; both had high impact strength and good tensile and bending resistance. Sorghum straw/PLA/PBAT composite and rice straw /PLA/PBAT composite had little difference in mechanical properties; both had high impact strength and good tensile and bending resistance.

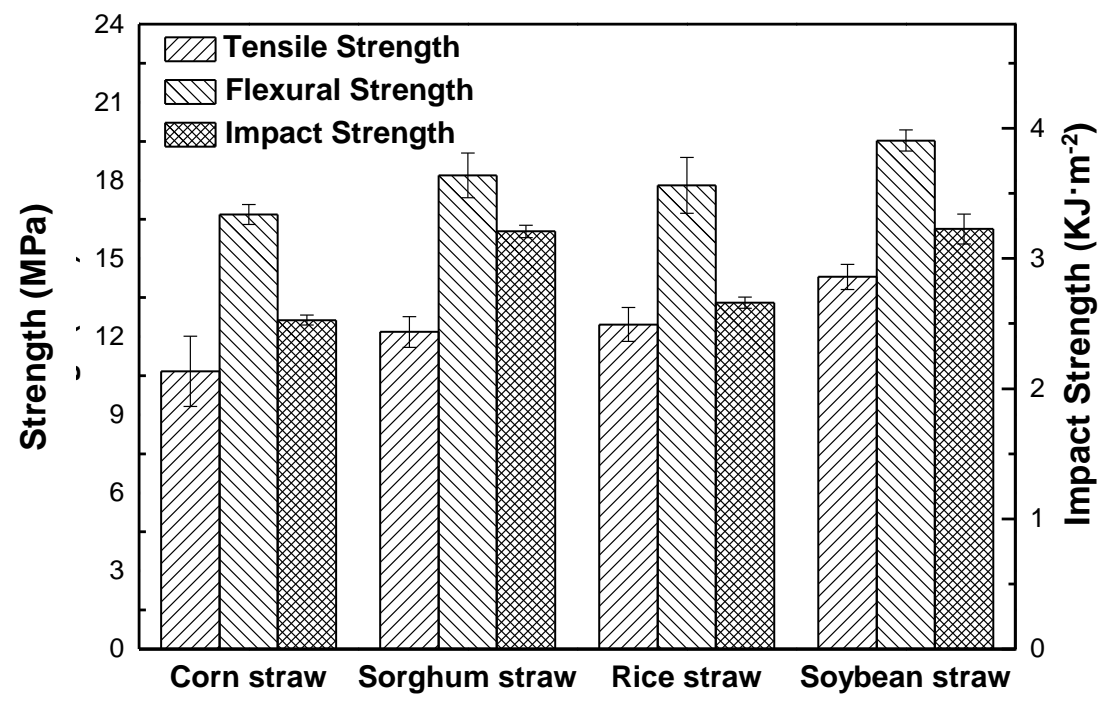

Fig. 2. Mechanical properties of straw fiber /PLA/PBAT wood plastic composites

\section{Microstructure Analysis}

Figure 3 shows the tensile section microstructure of four kinds of straw fiber/PLA/PBAT wood-plastic composites. The straw fibers were tightly combined with the matrix material, and the tensile section had no obvious void defects. With PLA-gMAH being used to enhance the compatibilization of PLA, there was no obvious delamination between PLA and PBAT. The best interfacial quality of fiber and matrix material was soybean straw/PLA/PBAT composite; the worst combination was corn straw. The inner layer of corn straw had low tissue strength, and it easily absorbed water, as shown in Fig. 1c. The fiber structure of corn straw was very loose, which affects the mechanical properties of the composite and causes the formation of fine cracks due to water vapor in the hot-press molding process. The loose structure makes it difficult for the matrix and fiber to come into close contact, resulting in poor interfacial quality of the tensile section. 


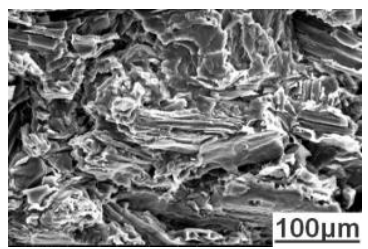

(a)

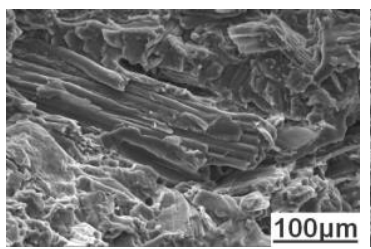

(b)

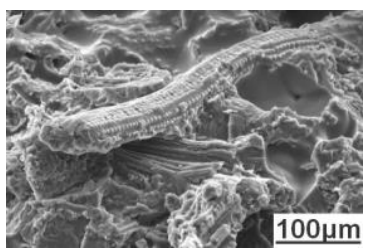

(c)

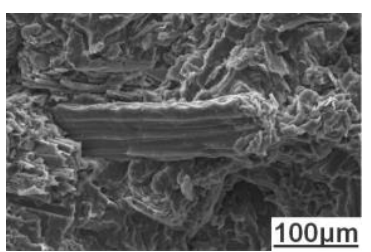

(d)

Fig. 3. Microscopic tensile sections of straw fiber/PLA/PBAT composites using (a) sorghum, (b) rice, (c) corn, (d) soybean

The physical properties of soybean straw are similar to sawdust, and its strength is high. After modification treatment, the surface roughness of soybean straw fiber is increased, and it is easy to be infiltrated by PLA/PBAT matrix in molten state (Chandrasekar et al. 2017). The interfacial friction between fiber and matrix is higher after the composite material is solidified, and it is still tightly combined with the matrix at the tensile section, thus improving its mechanical properties. The cross-sectional interfacial quality of the composite filled with sorghum straw and rice straw was similar, second only to that of the composite filled with soybean straw, but the interfacial quality was much higher than that of the composite filled with corn straw. These two kinds of fibers have compact structures and are easily wrapped by the matrix during hot pressing. Thus, the interfacial quality of the four kinds of straw fiber reinforced polylactic acid/PBAT composites is directly proportional to the surface roughness, stiffness, and structural compactness of the straw fibers.

\section{Thermal Properties Analysis}

The TG/DTG curves of four kinds of straw/PLA/PBAT composites and four kinds of straw fibers after treatment are shown in Fig. 4. The weight loss process was mainly divided into three parts. From $100{ }^{\circ} \mathrm{C}$ to $200{ }^{\circ} \mathrm{C}$, there was a slight decline in mass due to the evaporation of water and volatilization of a few small molecular compounds. Between $200{ }^{\circ} \mathrm{C}$ and $450{ }^{\circ} \mathrm{C}$, all curves exhibited an extremely fast decline rate. During this process, the mass loss was mainly caused by decomposition of straw fiber and matrix. In fiber, cellulose (180 to $240{ }^{\circ} \mathrm{C}$ ), hemicellulose $\left(230\right.$ to $310{ }^{\circ} \mathrm{C}$ ), and lignin $\left(300\right.$ to $400{ }^{\circ} \mathrm{C}$ ) (Ramiah 1970; Zeriouh and Belkbir 1995; Yang et al. 2007) are decomposed in sequence. The pyrolysis temperature of PLA is also between $260{ }^{\circ} \mathrm{C}$ and $400{ }^{\circ} \mathrm{C}$ (Arrieta et al. 2013; Wojtyła et al. 2017).

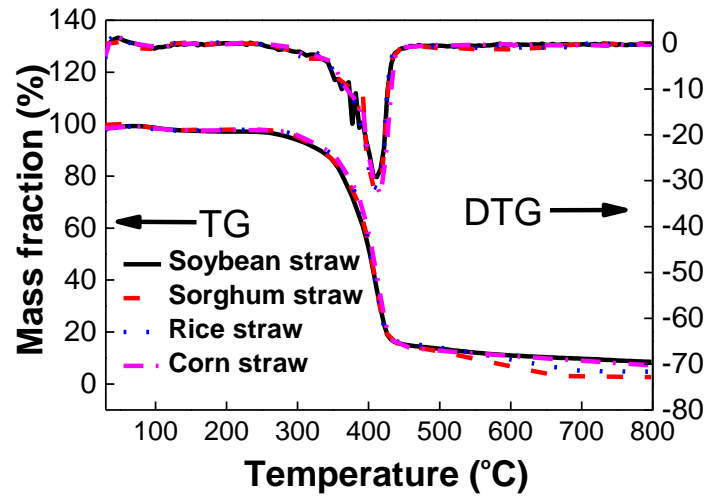

(a)

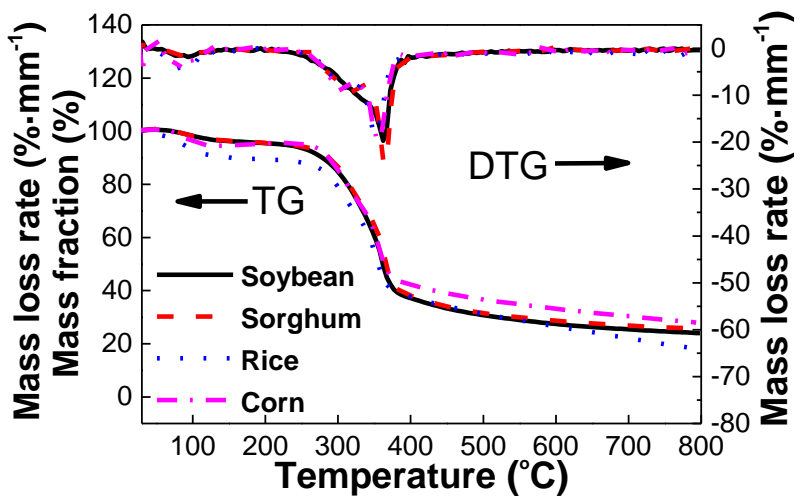

(b)

Fig. 4. TG/DTG of composites (a) and TG/DTG of straw (b) 
When the temperature rises to $500{ }^{\circ} \mathrm{C}$, the third stage starts. A few non-pyrolyzed components continue to decompose and the pyrolysis residues are further carbonized, and the continuous decline in quality is not severe and gradually tends to be stable. It can be seen from the figure that the corn straw /PLA/PBAT composite was superior to the other three materials in terms of initial thermal degradation temperature $\left(286.1^{\circ} \mathrm{C}\right)$, pyrolysis speed, and pyrolysis residue (7.27\%), so its thermal stability can be regarded as the best.

Comparing Fig. $4 \mathrm{a}$ with $4 \mathrm{~b}$, the main mass loss temperature range of the composite was 250 to $450{ }^{\circ} \mathrm{C}$, and the main mass loss temperature range of the fiber was 200 to $380{ }^{\circ} \mathrm{C}$; The residual amount of composites was lower than $10 \%$, while that of fibers was higher than $15 \%$. It can be seen from TG that the mass loss rate of the composite in the main mass loss interval was more severe than that of the fiber. The lowest pyrolysis temperature of PLA was $260{ }^{\circ} \mathrm{C}$. Straw fibers in the composite were wrapped by the matrix, and it was difficult for the fibers to reach the surface temperature of the material through the matrix wrapping them, resulting in the initial pyrolysis temperature of the composite being slightly higher than that of pure fibers and the pyrolysis temperature span of the composite material is longer than that of pure fibers. The PLA/PBAT content in the composite material was the highest, and its pyrolysis mainly produces $\mathrm{H}_{2} \mathrm{O}$ and $\mathrm{CO}_{2}$ (Wang et al. 2009), which is lower than that of pure fiber residue, i.e. the residual rate is lower.

\section{CONCLUSIONS}

1. The mechanical properties of soybean straw/PLA/PBAT composites were the best, with tensile strength, flexural strength, and impact strength of 14.3 $\mathrm{MPa}, 19.3 \mathrm{MPa}$, and $3.23 \mathrm{KJ} \cdot \mathrm{m}^{-2}$, respectively. The mechanical properties of corn straw/PLA/PBAT composites were the worst, with the three properties decreased by $25.3 \%, 14.6 \%$, and $27.8 \%$, respectively.

2. Due to the loose structure of the corn straw inner core, it is difficult to be completely soaked by the matrix. The kind of composite interface filled with corn straw exhibited the worst interfacial quality.

3. The TG curves of the four kinds of straw/PLA/PBAT composites were similar. The thermal stability of corn straw/PLA/PBAT composites was the best. The initial decomposition temperature was $286.1^{\circ} \mathrm{C}$, and the residual rate was $7.27 \%$ for the corn straw/PLA/PBAT composites.

\section{ACKNOWLEDGEMENT}

This work was financially supported by the Fundamental Research Funds for the Central Universities (Y0201800586) and the Regional Cooperative Innovation in Autonomous Region (2019E0241). 


\section{REFERENCES CITED}

Arrieta, M. P., Parres, F., López, J., and Jiménez, A. (2013). "Development of a novel pyrolysis-gas chromatography/mass spectrometry method for the analysis of poly (lactic acid) thermal degradation products," Journal of Analytical and Applied Pyrolysis 101, 150-155. DOI:10.1016/j.jaap.2013.01.017.

Cardoso, E. C. L., Oliveira, R. R., Machado, G. A. F., and Moura, E. A. (2017). "Study of flexible films prepared from PLA/PBAT blend and PLA E-beam irradiated as compatibilizing agent," in: Characterization of Minerals, Metals, and Materials 2017 (pp. 121-129). Springer, Cham. DOI:10.1007/978-3-319-51382-9_14.

Chandrasekar, M., Ishak, M. R., Sapuan, S. M., Leman, Z., and Jawaid, M. (2017). “A review on the characterisation of natural fibres and their composites after alkali treatment and water absorption," Plastics, Rubber and Composites 46(3), 119-136. DOI:10.1080/14658011.2017.1298550.

Chen, X., Guo, Q., and Mi, Y. (1998). "Bamboo fiber-reinforced polypropylene composites: A study of the mechanical properties," Journal of Applied Polymer Science 69(10), 1891-1899. DOI:10.1002/(SICI)10974628(19980906)69:10<1891::AID-APP1>3.0.CO;2-9

Dharmalingam, S., Hayes, D. G., Wadsworth, L. C., Dunlap, R. N., DeBruyn, J. M., Lee, J., and Wszelaki, A. L. (2015). "Soil degradation of polylactic acid/polyhydroxyalkanoate-based nonwoven mulches," Journal of Polymers and the Environment 23(3), 302-315. DOI:10.1007/s10924-015-0716-9.

Fu, J., He, C., Chang, X., Wang, X., Xiong, J., and Liu, J. (2016). “Thermo-stability and microstructure of wheat straw/polypropylene foamed composites," Acta Materiae Compositae Sinica 33(3), 469-476.

GB/T 1040.1-2006. "Plastics - Determination of tensile properties." Standardization Administration of China, Beijing, China.

GB/T9341-2008. "Plastics - Determination of flexural properties," Standardization Administration of China, Beijing, China.

GB/T 1043.1-2008. "Plastics - Determination of Charpy impact properties," Standardization Administration of China, Beijing, China.

Ge, X. W., Wang, L. H., Hou, J. J., Rong, B. B., Yue, X. Q., and Zhang, S. M. (2016). "Relationship among microstructure, mechanical properties and chemical compositions in Populus cathayana sapwood during brown-rot decay," Journal of Beijing Forestry University 38(10), 112-122.

Jiang, L., He, C., Fu, J., and Chen, D. (2017). "Wear behavior of straw fiber-reinforced polyvinyl chloride composites under simulated acid rain conditions," Polymer Testing 62, 373-381. DOI:10.1016/j.polymertesting.2017.07.028.

Kolling, O. W. (1992). "FTIR study of the solvent influence on the carbonyl absorption peak of ethyl acetate," The Journal of Physical Chemistry 96(15), 6217-6220. DOI:10.1021/j100194a025.

Lee, B. K., Yun, Y., and Park, K. (2016). "PLA micro-and nano-particles," Advanced Drug Delivery Reviews 107, 176-191. DOI:10.1016/j.addr.2016.05.020.

Li, L., and Chen, H. T. (2011). "Study on the physical and chemical and mechanical pulping characteristic of soybean straw fiber," In 2011 International Conference on Materials for Renewable Energy \& Environment (Vol. 2, pp. 1491-1494).

IEEE.DOI:10.1109/ICMREE.2011.5930616.

Murariu, M., and Dubois, P. (2016). "PLA composites: From production to 
properties," Advanced Drug Delivery Reviews 107, 17-46.

DOI:10.1016/j.addr.2016.04.003.

Ramiah, M. V. (1970). "Thermogravimetric and differential thermal analysis of cellulose, hemicellulose, and lignin," Journal of Applied Polymer Science 14(5), 1323-1337. DOI:10.1002/app.1970.070140518.

Rasselet, D., Caro-Bretelle, A. S., Taguet, A., and Lopez-Cuesta, J. M. (2019). "Reactive compatibilization of PLA/PA11 blends and their application in additive manufacturing," Materials 12(3), 485. DOI:10.3390/ma12030485.

Torres, J., Cotelo, J., Karl, J., and Gordon, A. P. (2015). "Mechanical property optimization of FDM PLA in shear with multiple objectives," Jom 67(5), 1183-1193. DOI:10.1007/s11837-015-1367-y.

Wach, R. A., Wolszczak, P., and Adamus-Wlodarczyk, A. (2018). "Enhancement of mechanical properties of FDM-PLA parts via thermal annealing," Macromolecular Materials and Engineering 303(9), 1800169. DOI:10.1002/mame.201800169.

Wang, C. H., and Liu, S. K. (2015). "Effect of alkali treatment on properties of bamboo fiber and bamboo fiber reinforced polypropylene composites," Acta Materiae Compositae Sinica 32(3), 683-690.

Wang, G., Li, A. M., and Quan, C. (2009). "Thermal decomposition of biomass/polylactic acid during co-pyrolysis," Journal of Ciesc Journal 60(7), 1787-1792.

Wojtyła, S., Klama, P., and Baran, T. (2017). "Is 3D printing safe? Analysis of the therm al treatment of thermoplastics: ABS, PLA, PET, and nylon," Journal of Occupational and Environmental Hygiene 14(6), D80-D85.DOI:10.1080/15459624.2017.1285489.

Xu, J., Zhang, J., Gao, W., Liang, H., Wang, H., and Li, J. (2009). "Preparation of chitosan/PLA blend micro/nanofibers by electrospinning," Materials Letters 63(8), 658- 660. DOI:10.1016/j.matlet.2008.12.014.

Xu, Z., Yang, L., Ni, Q., Ruan, F., and Wang, H. (2019). "Fabrication of highperformance green hemp/polylactic acid fibre composites," Journal of Engineered Fibers and Fabrics 14, 1558925019834497. DOI:10.1177/1558925019834497.

Yang, H., Yan, R., Chen, H., Lee, D. H., and Zheng, C. (2007). "Characteristics of hemicellulose, cellulose and lignin pyrolysis," Fuel 86(12-13), 1781-1788. DOI:10.1016/j.fuel.2006.12.013.

Zeriouh, A., and Belkbir, L. (1995). "Thermal decomposition of a Moroccan wood under a nitrogen atmosphere," Thermochimica Acta 258, 243-248. DOI:10.1016/00406031(94)02246-K.

Zhu, Z., Hao, M., and Zhang, N. (2018). "Influence of contents of chemical compositions on the mechanical property of sisal fibers and sisal fibers reinforced PLA composites," Journal of Natural Fibers 1-12. DOI:10.1080/15440478.2018.1469452.

Article submitted: October 25, 2019; Peer review completed: December 15, 2019;

Revised version received: January 10, 2020; Accepted: February 16, 2020; Published: February 21, 2020.

DOI: 10.15376/biores.15.2.2596-2604 